Editorial Communication

\title{
RETRACTED
}

\section{ADSORPTION OF METHYLENE BLUE BY DIFFERENT TYPES OF STRAW BIOCHAR WITH PERFORMANCE COMPARISON}

This article has been retracted on $2^{\text {nd }}$ January 2021 by the authors. 